\title{
CHẤT LƯỢNG CUỘC SỐNG VÀ MỌT SÓ YÊU TỐ LIÊN QUAN Ở NGƯỜ' BỆNH SUY THẬN MẠN LỌC MÁU CHU KỲ TẠI BỆNH VIỆN ĐA KHOA NÔNG NGHIỆP TRONG ĐẠI DỊCH COVID-19
}

\author{
Phan Thị Dung1, ${ }^{凶}$, Đỗ Thị Ngọc Thục² \\ 'Trường Đại học Kinh doanh và Công nghệ Hà Nội \\ ²Bệnh viện Đa khoa Nông nghiệp
}

Nghiên cứu được thực hiện nhằm khảo sát chất lượng cuộc sống và một số yếu tố liên quan ở người bệnh suy thận mạn lọc máu chu kỳ tại Bệnh viện Đa khoa Nông nghiệp. Phương pháp: Thiết kế nghiên cứu mô tả cắt ngang, đã được thực hiện từ tháng 2 đến tháng 10 năm 2020 trên toàn bộ 201 người bệnh. Kết quả: Nghiên cứu 201 người bệnh cho thấy: Chất lượng cuộc sống của người bệnh suy thận mạn ở mức độ trung bình (mean $=50.2, S D=15,0$ ). Trong đó, giới hạn vai trò do vấn đề cảm xúc ở mức cao nhất (mean $=80,3$, $S D=37,9$ ); sức khỏe tổng thể ở mức thấp nhất (mean = 39,6, $S D=19,3$ ). Chất lượng cuộc sống của người bệnh suy thận mạn có mối tương quan với năng lực sức khỏe, dinh dưỡng, chế độ ăn lành mạnh, sức khỏe tâm thần, thực hành phòng dịch COVID-19. Kết luận: Chất lượng cuộc sống của người bệnh suy thận mạn ở mức độ trung bình. Có mối tương quan giữa chất lượng cuộc sống của người bệnh suy thận mạn với năng lực sức khỏe, dinh dương, chế độ ăn lành mạnh, sức khỏe tâm thần và thực hành phòng dịch COVID-19.

Từ khóa: Dịch bệnh COVID-19; người bệnh suy thận mạn.

\section{I. ĐẠT VẤN ĐÊ}

Bệnh thận mạn giai đoạn cuối (BTMGĐC) là bệnh lý suy giảm dần và không hồi phục chức năng thận do nhiều nguyên nhân khác nhau. Theo thống kê ở Mỹ năm 2007 có khoảng 26 triệu người mắc bệnh thận mạn chiếm tỷ lệ khoảng 13,1\% và khoảng 1400/1 triệu người mắc $B T M G Đ C .{ }^{8}$ Tại Pháp mỗi năm có khoảng 4800 đến 6000 ca mới mắc BTMGĐC ${ }^{4}{ }^{4}$ ỏ Nhật Bản và Đài Loan là khoảng gần 2400 ca. ${ }^{1}$ Người ta dự báo cứ một người bệnh được điều trị thay thế thận thì có tới 100 người đang mắc bệnh thận mạn ở các giai đoạn khác nhau. ${ }^{1}$ Tại Việt Nam ước tính có khoảng 8 triệu người mắc bệnh thận mạn, chiếm khoảng $10 \%$ dân số, trong đó $3,1 \%$ đến 3,6\% bệnh thận mạn tiến

Tác giả liên hệ: Phan Thị Dung

Trường Đại học Kinh doanh và Công nghệ Hà Nội

Email: phanthidzungvd@gmail.com

Ngày nhận: 04/05/2021

Ngày được chấp nhận: 09/06/2021 triển từ giai đoạn III đến giai đoạn $\mathrm{V}^{6}$.

Sự bùng phát của bệnh viêm đường hô hấp cấp do virus coronavirus mới (COVID-19) được phát hiện lần đầu tiên vào tháng 12 năm 2019 tại Vũ Hán, Trung Quốc. ${ }^{5}$ COVID-19 đã lan rộng đến nhiều quốc gia đang phát triển và được công nhận là mối quan tâm về sức khỏe toàn cầu, khiến các tổ chức y tế công cộng toàn cầu phải cảnh giác cao. ${ }^{7}$ Tổ chức $Y$ tế Thế giới (WHO) tuyên bố tình trạng khẩn cấp COVID-19 là trường hợp khẩn cấp y tế công cộng thứ sáu được quốc tế quan tâm vào ngày 30 tháng 1 năm 202. ${ }^{11}$ Theo báo cáo vào ngày 24 tháng 3 năm 2020, tổng số người được chẩn đoán mắc COVID-19 là 372.757 trường hợp, với 16.231 trường hợp tử vong ở 170 quốc gia/khu vực; Trong số này, 123 trường hợp đã được báo cáo tại Việt Nam. ${ }^{3}$ COVID-19 đã chính thức được tuyên bố là đại dịch bởi WHO vào ngày 11 tháng 3 năm 2020. ${ }^{9}$ Phương pháp điều trị 
và vắc-xin cho COVID-19 hiện đang được phát triển. Do đó, việc phòng ngừa và chăm sóc hỗ trợ rất được khuyến khích, ${ }^{3}$ đặc biệt là ở các nước có hệ thống chăm sóc sức khỏe yếu hơn, theo đề xuất của Tổng giám đốc WHO Tedros Adhanom Ghebreyesus. ${ }^{12}$

Năng lực sức khỏe, sức khỏe tâm thần của người bệnh (NB) suy thận mạn lọc máu chu kỳ tại khoa Thận-Niệu-Lọc máu Bệnh viện Đa khoa Nông nghiệp (BVĐKNN) có thể thay đổi trong thời gian đại dịch bệnh COVID -19 toàn cầu diễn ra. Vì vậy, chúng tôi thực hiện nghiên cứu này với 2 mục tiêu:

1) Khảo sát chất lượng cuộc sống của người bệnh suy thận mạn lọc máu chu kỳ trong đại dịch Covid-19 toàn cầu tại Bệnh viện Đa khoa Nông nghiệp;

2) Xác định một số yếu tố liên quan đến chất lượng cuộc sống của người bệnh suy thận mạn lọc máu chu kỳ tại Bệnh viện Đa khoa Nông nghiệp.

\section{II. ĐỐI TƯỢNG VÀ PHƯO'NG PHÁP}

\section{1. Đối tượng}

Nghiên cứu mô tả cắt ngang, được thực hiện tại Bệnh viện Đa khoa Nông nghiệp. Từ tháng 2 đến ngày 10 năm 2020 trên toàn bộ 201 người bệnh suy thận mạn lọc máu chu kỳ, tỉnh táo, tiếp xúc tốt và đồng ý tham gia nghiên cứu.

\section{Phương pháp}

\section{Bộ câu hỏi tự điền gồm:}

1) Thông tin cơ bản gồm 11 câu: ${ }^{4}$ tuổi, giới tính, trình trạng hôn nhân, trình độ văn hóa, nghề nghiệp, thu nhập trung bình/hộ gia đình, khả năng chi trả các dịch vụ y tế, địa vị xã hội,đối tượng nghi phơi nhiễm với Covid từ F1 đến F6, triệu chứng nghi nghờ COVID 19;

2) Thực hành phòng chống dịch gồm 3 câu: thực hiện vệ sinh bàn tay, giữ khoảng cách, đeo khẩu trang. Điểm từ 1 đến 3 , phạm vi điểm 3-15, với số điểm càng cao, việc tuân thủ các biện pháp phòng chống lây nhiễm với COVID-19 càng tốt;

3) Năng lực sức khỏe điện tử thang đo gồm 8 câu dùng để đánh giá kỹ năng tìm kiếm thông tin. ${ }^{10}$ bộ câu hỏi hợp lệ và đáng tin cậy dựa trên thanh đo Likert 5 điểm từ 1 = hoàn toàn không đồng ý, đến $5=$ hoàn toàn đồng ý. Điểm số dao động từ 8 đến 40 , với điểm số cao, khả năng đọc hiểu về sức khỏe tốt hơn;

4) Hiểu biết về sức khỏe gồm 12 câu đã được sử dụng để đánh giá mức hiểu biết về sức khỏe. ${ }^{3,11}$ Các chỉ số hiểu biết sức khỏe đã được chuẩn hóa thành số đo thống nhất từ 0 đến 50 (0 là giá trị hiểu biết sức khỏe thấp nhất và 50 là cao nhất);

5) Năng lực về dinh dưỡng điện tử gồm 7 câu;

6) Chế độ ăn lành mạnh gồm 6 câu.

7) Chất lượng cuộc sống liên quan đến sức khỏe (HRQoL) được đo lường bằng phiếu khảo sát gồm 36 mục (SF-36), được phát triển tại Công ty Cổ phần Nghiên cứu và Phát triển (RAND). ${ }^{5}$ Độ tin cậy và tính hợp lệ của thang đo này đã được sử dụng trong các nghiên cứu trước đây. ${ }^{7,16}$ Phương pháp chấm điểm của RAND-36 do RAND Corporation hướng dẫn. ${ }^{8,14}$ khoảng điểm từ 0 đến 100 , với điểm số cao hơn cho thấy chất lượng cuộc sống tốt hơn.

Sau khi nhận được chấp thuận của Hội đồng đạo đức, nhóm nghiên cứu được tập huấn về phương pháp thu thập số liệu. Tiếp cận với từng đối tượng, giải thích mục đích của nghiên cứu. Đối tượng đồng ý tham gia, ký vào giấy chấp thuận và hoàn thành bộ câu hỏi phát vấn theo thời gian thuận tiện và gửi lại nghiên cứu viên.

\section{Xử lý số liệu}

Sau khi thu thập, số liệu được kiểm tra làm sạch, nhập bằng phần mềm Epidata và phân tích bằng phần mềm SPSS 22.0 với mức ý nghĩa thống kê $p<0.05$. Kiểm định: Independent 
T-test, one-way ANOVA, Chi-square.

\section{4. Đạo đức nghiên cứu}

Nghiên cứu thực hiện khi đã được Hội đồng Khoa học và Công nghệ Bệnh viện Đa khoa Nông nghiệp thông qua theo Quyết định số 426 ngày 18 tháng 3 năm 2020 và Hội đồng đạo đức trường $Y$ tế công cộng thông qua ngày 20 tháng 7 năm 2020, số 204/2020/YTCC-HD3.

\section{KẾT QUẢ}

\section{1. Đặc điểm của đối tượng nghiên cứu}

Theo nghiên cứu của chúng tôi, nhóm tuổi từ 40 - 59 chiếm tỷ lệ cao nhất 45,3\%; nhóm tuổi > 60 chiếm 36,8\%; nhóm tuổi 20 - 39 chiếm tỷ lệ 16,4\%. Người bệnh là nam chiếm $55,2 \%$ người bệnh nư chiếm 44,8\%. Người bệnh có trình độ văn hóa dưới THPT chiếm tỷ lệ cao nhất $80,6 \%$ người bệnh có trình độ học nghề, trung cấp/cao đẳng chiếm 14,4\% người bệnh có trình độ đại học/sau đại học chiếm tỷ lệ thấp nhất $5 \%$.

Bảng 1. Chất lượng cuộc sống của người bệnh suy thận mạn trong đại dịch COVID-19 ( $\mathrm{N}=201$, phạm vi điểm từ 0-100)

\begin{tabular}{lcc}
\hline \multicolumn{1}{c}{ Danh mục } & Tiểu mục & $\begin{array}{c}\text { Điểm trung bình } \\
\text { (mean } \pm \text { SD) }\end{array}$ \\
\hline Hoạt động thể chất & $3,4,5,6,7,8,9,10,11,12$ & $42,4 \pm 24,7$ \\
\hline Giới hạn vai trò do sức khỏe thể chất & $13,14,15,16$ & $56,3 \pm 48,9$ \\
\hline Giới hạn vai trò do vấn đề cảm xúc & $17,18,19$ & $80,3 \pm 37,9$ \\
\hline Năng lượng/mệt mỏi & $23,27,29,31$ & $49,6 \pm 9,3$ \\
\hline Tình cảm tốt đẹp & $24,25,26,28,30$ & $53,5 \pm 7,6$ \\
\hline Hoạt động xã hội & 20,32 & $56,6 \pm 15,8$ \\
\hline Đau & 21,22 & $53,5 \pm 22,8$ \\
\hline Sức khỏe tổng thể & $1,33,34,35,36$ & $39,6 \pm 19,3$ \\
\hline Tổng điểm & $1-36$ & $50,2 \pm 15,0$ \\
\hline
\end{tabular}

Lưu ý: Tất cả câu hỏi đều được tính trên thang điểm từ 0 đến 100; 100 điểm tương ứng với mức độ cao nhất có thể; $S D$, độ lệch chuẩn.

Với thang điểm từ 0 đến 100 , chất lượng cuộc sống của người bệnh suy thận mạn ở mức độ trung bình (mean $=50,2, S D=15,0$ ). Trong đó, giới hạn vai trò do vấn đề cảm xúc ở mức cao nhất (mean = 80,3, SD = 37,9); sức khỏe tổng thể ở mức thấp nhất (mean = 39,6, SD = 19,3).

Mối tương quan giữa chất lượng cuộc sống và năng lực sức khỏe, dinh dưỡng, chế độ ăn lành mạnh, sức khỏe tâm thần, thực hành phòng dịch của người bệnh suy thận mạn.

Chất lượng cuộc sống của người bệnh suy thận mạn có mối tương quan với năng lực sức khỏe, dinh dưỡng, chế độ ăn lành mạnh, sức khỏe tâm thần, thực hành phòng dịch COVID-19. Theo đó, người bệnh có năng lực sức khỏe, dinh dưỡng, chế độ ăn lành mạnh, sức khỏe tâm thần và thực hành phòng dịch càng cao thì chất lượng cuộc sống càng cao. 
Bảng 2. Mối tương quan giữa chất lượng cuộc sống và năng lực sức khỏe, dinh dưỡng, chế độ ăn lành mạnh, sức khỏe tâm thần, thực hành phòng dịch của người bệnh suy thận mạn ( $N=201)$

\begin{tabular}{|c|c|c|c|}
\hline & $\begin{array}{c}\text { Mean } \pm \text { SD } \\
\text { n (\%) }\end{array}$ & $\begin{array}{c}\text { HRQoL } \\
\text { (Mean } \pm \text { SD/ Median) }\end{array}$ & $\mathbf{p}$ \\
\hline $\begin{array}{l}\text { Năng lực sức khỏe điện tử (eHL) } \\
\text { (phạm vi điểm từ } 8 \text { - 40) }\end{array}$ & $24,6 \pm 7,5$ & $50,2 \pm 15,0$ & $0,003^{a}$ \\
\hline $\begin{array}{l}\text { Năng lực sức khỏe (HL), } \\
\text { (phạm vi điểm từ } 0 \text { - 50) }\end{array}$ & $15,2 \pm 12,4$ & $50,2 \pm 15,0$ & $0,003^{a}$ \\
\hline $\begin{array}{l}\text { Năng lực chế độ ăn lành mạnh điện tử } \\
\text { (phạm vi điểm từ } 4 \text { - 16) }\end{array}$ & $8,3 \pm 3,7$ & $50,2 \pm 15,0$ & $<0,001 a$ \\
\hline \multicolumn{4}{|l|}{ Năng lực dinh dưỡng điện tử } \\
\hline Tra cứu thông tin, phạm vi điểm từ 3 - 15 & $6,4 \pm 2,8$ & $50,2 \pm 15,0$ & $<0,001^{\mathrm{a}}$ \\
\hline Hiểu thông tin, phạm vi điểm từ 4 - 12 & $10,0 \pm 2,9$ & $50,2 \pm 15,0$ & $<0,001^{a}$ \\
\hline Đánh giá thông tin, phạm vi điểm từ 2 - 10 & $6,8 \pm 1,6$ & $50,2 \pm 15,0$ & $0,02^{\mathrm{a}}$ \\
\hline Áp dụng thông tin, phạm vi điểm từ 2 - 10 & $2,5 \pm 2,4$ & $50,2 \pm 15,0$ & $0,665^{\mathrm{a}}$ \\
\hline $\begin{array}{l}\text { Chế độ ăn lành mạnh } \\
\text { (phạm vi điểm từ } 0 \text { - 25) }\end{array}$ & $13,6 \pm 4,1$ & $50,2 \pm 15,0$ & $0,001^{a}$ \\
\hline \multicolumn{4}{|l|}{ Sức khỏe tâm thần } \\
\hline Mức độ trầm cảm & & & $<0,001^{b}$ \\
\hline Không (PHQ < 10) & $180(89,6)$ & 54,2 & \\
\hline Có (PHQ $\geq 10)$ & $21(10,4)$ & 29,7 & \\
\hline Mức độ lo âu (GAD) & & & $<0,001^{b}$ \\
\hline Không (GAD < 8) & $184(91,5)$ & 53,8 & \\
\hline Có (GAD $\geq 8)$ & $17(8,5)$ & 27,1 & \\
\hline $\begin{array}{l}\text { Lo sọ̣ về COVID-19 } \\
\text { (phạm vi điểm từ } 7 \text { - 35) }\end{array}$ & $24,8 \pm 5,3$ & $50,2 \pm 15,0$ & \\
\hline $\begin{array}{l}\text { Thực hành phòng lây nhiễm COVID-19 } \\
\text { (phạm vi điểm từ } 3 \text { - 15) }\end{array}$ & $13,1 \pm 2,1$ & $50,2 \pm 15,0$ & \\
\hline
\end{tabular}

Lưu ý. HRQoL, chất lượng cuộc sống liên quan đến sức khỏe; $P H Q-9$, bộ câu hỏi sức khỏe người bệnh 9 tiểu mục; GAD, Rối loạn lo âu chung; COVID-19, dịch bệnh do vi rút corona 2019; $n$, tần xuất; \%, phần trăm; $S D$, độ lệch chuẩn; * $p<.05$, ${ }^{a}$ Spearman correlation, ${ }^{b}$ Mann-Whitney U-test.

Yếu tố ảnh hưởng đến sức khỏe tâm thần gồm địa vị xã hội và nghi nhiễm COVID-19. Ngoài ra, thay đổi hoạt động thể lực so với trước dịch bệnh cũng có ảnh hưởng đến mức độ trầm cảm của người bệnh. 
Bảng 3. Các yếu tố ảnh hưởng đến sức khỏe tâm thần của người bệnh suy thận mạn ( $\mathrm{N}=201)$

\begin{tabular}{|c|c|c|c|c|c|c|}
\hline & $\begin{array}{l}P H Q<10 \\
(N=180)\end{array}$ & $\begin{array}{c}P H Q \geq 10 \\
(N=21)\end{array}$ & & $\begin{array}{l}\text { GAD }<8 \\
(N=184)\end{array}$ & $\begin{array}{l}\text { GAD } \geq 8 \\
(N=17)\end{array}$ & \\
\hline & n (\%) & n (\%) & $\mathbf{p}$ & n (\%) & n (\%) & $\mathbf{p}$ \\
\hline Tuổi, năm & & & 0.732 & & & 0,818 \\
\hline$<20$ & $3(1,5)$ & $0(0)$ & & $3(1,5)$ & $0(0)$ & \\
\hline $20-39$ & $31(15,4)$ & $2(1,0)$ & & $29(14,4)$ & $4(2,0)$ & \\
\hline $40-59$ & $81(40,3)$ & $10(5,0)$ & & $84(41,8)$ & $7(3,5)$ & \\
\hline$\geq 60$ & $65(32,3)$ & $9(4,5)$ & & $68(33,8)$ & $6(3,0)$ & \\
\hline Giới & & & 0,782 & & & 0,479 \\
\hline Nam & $100(49,8)$ & $11(5,5)$ & & $103(51,2)$ & $8(4,0)$ & \\
\hline Nữ & $80(39,8)$ & $10(5,0)$ & & $81(40,3)$ & $9(4,5)$ & \\
\hline Tình trạng hôn nhân & & & NA & & & NA \\
\hline Chưa kết hôn & $3(1,5)$ & $0(0)$ & & $3(1,5)$ & $0(0)$ & \\
\hline Đã kết hôn & $177(88,1)$ & $21(10,4)$ & & $181(90,0)$ & $17(8,5)$ & \\
\hline Khả năng chi trả y tế & & & NA & & & NA \\
\hline Rất hoặc tương đối khó & $174(86,6)$ & $21(10,4)$ & & $178(88,6)$ & $17(8,5)$ & \\
\hline Rất hoặc tương đối dễ & $6(3,0)$ & $0(0)$ & & $6(3,0)$ & $0(0)$ & \\
\hline Địa vị xã hội & & & $<0,001$ & & & 0,038 \\
\hline Thấp & $148(73,6)$ & $10(5,0)$ & & $148(73,6)$ & $10(5,0)$ & \\
\hline Trung bình hoặc cao & $32(15,9)$ & $11(5,5)$ & & $36(17,9)$ & $7(3,5)$ & \\
\hline Đối tượng nghi nhiễm COVID- & & & 0,001 & & & 0,028 \\
\hline Không & $156(77,6)$ & $12(6,0)$ & & $157(78,1)$ & $11(5,5)$ & \\
\hline Có & $24(11,9)$ & $9(4,5)$ & & $27(13,4)$ & $6(3,0)$ & \\
\hline Dấu hiệu nghi nhiễm COVID-1 & & & 0,094 & & & 0,112 \\
\hline Không & $154(76,6)$ & $15(7,5)$ & & $157(78,1)$ & $12(6,0)$ & \\
\hline Có & $26(12,9)$ & $6(3,0)$ & & $27(13,4)$ & $5(2,5)$ & \\
\hline Trình độ văn hóa & & & 0,406 & & & 0,575 \\
\hline THPT trở xuống & $143(71,1)$ & $19(9,5)$ & & $147(73,1)$ & $15(7,5)$ & \\
\hline Học nghề/Trung cấp/Cao đẳng & $28(13,9)$ & $1(0,5)$ & & $28(13,9)$ & $1(0,5)$ & \\
\hline Đại học/Sau đại học & $9(4,5)$ & $1(0,5)$ & & $9(4,5)$ & $1(0,5)$ & \\
\hline
\end{tabular}




\begin{tabular}{|c|c|c|c|c|c|c|}
\hline & $\begin{array}{l}P H Q<10 \\
(N=180)\end{array}$ & $\begin{array}{c}P H Q \geq 10 \\
(N=21)\end{array}$ & & $\begin{array}{l}\text { GAD }<8 \\
(N=184)\end{array}$ & $\begin{array}{l}\text { GAD } \geq 8 \\
(N=17)\end{array}$ & \\
\hline & n (\%) & n (\%) & $\mathbf{p}$ & n (\%) & n (\%) & p \\
\hline Bệnh lý kèm theo & & & NA & & & NA \\
\hline Một hoặc nhiều & $180(89,6)$ & $21(10,4)$ & & $184(91,5)$ & $17(8,5)$ & \\
\hline Không & $0(0)$ & $0(0)$ & & $0(0)$ & $0(0)$ & \\
\hline Nghề nghiệp & & & 0,679 & & & 0,289 \\
\hline Tư nhân/Nhà nước & $5(2,5)$ & $1(0,5)$ & & $5(2,5)$ & $1(0,5)$ & \\
\hline Kinh doanh tự do & $36(17,9)$ & $2(1,0)$ & & $37(18,4)$ & $1(0,5)$ & \\
\hline Thất nghiệp/Phụ thuộc & $123(61,2)$ & $16(8,0)$ & & $127(63,2)$ & $12(6,0)$ & \\
\hline Khác & $16(8,0)$ & $2(1,0)$ & & $15(7,5)$ & $3(1,5)$ & \\
\hline Hút thuốc so với trước dịch & OVID-19 & & NA & & & NA \\
\hline $\begin{array}{l}\text { Chưa bao giờ, bỏ } \\
\text { hoặc ít hơn }\end{array}$ & $179(89,1)$ & $21(10,4)$ & & $183(91,0)$ & $17(8,5)$ & \\
\hline $\begin{array}{l}\text { Không thay đổi } \\
\text { hoặc nhiều hơn }\end{array}$ & $1(0,5)$ & $0(0)$ & & $1(0,5)$ & $0(0)$ & \\
\hline Uống rượu, bia so với trước & dịch COVID. & & NA & & & NA \\
\hline $\begin{array}{l}\text { Chưa bao giờ, bỏ } \\
\text { hoặc ít hơn }\end{array}$ & $179(89,1)$ & $21(10,4)$ & & $183(91,0)$ & $17(8,5)$ & \\
\hline $\begin{array}{l}\text { Không thay đổi } \\
\text { hoặc nhiều hơn }\end{array}$ & $1(0,5)$ & $0(0)$ & & $1(0,5)$ & $0(0)$ & \\
\hline Hoạt động thể lực so với trưc & C dịch COV & D-19 & 0,034 & & & 0,151 \\
\hline $\begin{array}{l}\text { Chưa bao giò', bỏ } \\
\text { hoặc ít hơn }\end{array}$ & $153(76,1)$ & $14(7,0)$ & & $155(77,1)$ & $12(6,0)$ & \\
\hline $\begin{array}{l}\text { Không thay đổi } \\
\text { hoặc nhiều hơn }\end{array}$ & $27(13,4)$ & $7(3,5)$ & & $29(14,4)$ & $5(2,5)$ & \\
\hline Thay đổi chế độ ăn so với tru & óc dịch CO & IID-19 & 0,617 & & & 0,666 \\
\hline Kém lành mạnh hơn & $17(8,5)$ & $2(1,0)$ & & $17(8,5)$ & $2(1,0)$ & \\
\hline $\begin{array}{l}\text { Không thay đổi/lành mạnh } \\
\text { hơn }\end{array}$ & $163(81,1)$ & $19(9,5)$ & & $167(83,1)$ & $15(7,5)$ & \\
\hline $\begin{array}{l}\text { Thay đổi sức khỏe tâm thần } \\
\text { so với trước dịch COVID-19 }\end{array}$ & & & 0,320 & & & 0,707 \\
\hline Tệ hơn & $26(12,9)$ & $1(0,5)$ & & $24(11,9)$ & $3(1,5)$ & \\
\hline Không thay đổi hoặc tốt hơn & $154(76,6)$ & $20(10,0)$ & & $160(79,6)$ & $14(7,0)$ & \\
\hline
\end{tabular}




\begin{tabular}{|c|c|c|c|c|c|c|}
\hline & $\begin{array}{l}P H Q<10 \\
(N=180)\end{array}$ & $\begin{array}{c}P H Q \geq 10 \\
(N=21)\end{array}$ & & $\begin{array}{l}\text { GAD }<8 \\
(N=184)\end{array}$ & $\begin{array}{l}\text { GAD } \geq 8 \\
(N=17)\end{array}$ & \\
\hline & n (\%) & n (\%) & $\mathbf{p}$ & n (\%) & n (\%) & $\mathbf{p}$ \\
\hline $\begin{array}{l}\text { Thay đổi chất lượng cuộc số। } \\
\text { so với trước dịch COVID-19 }\end{array}$ & & & 0,577 & & & 0,162 \\
\hline Tệ hơn & $41(20,4)$ & $3(1,5)$ & & $38(18,9)$ & $6(3,0)$ & \\
\hline Không thay đổi hoặc tốt hơn & $139(89,6)$ & $18(9,0)$ & & $146(72,6)$ & $11(5,5)$ & \\
\hline
\end{tabular}

Lưu ý. PHQ, bộ câu hỏi sức khỏe người bệnh; GAD, rối loạn lo âu chung; COVID-19, dịch bệnh do vi rút corona 2019; $n$, tần xuất; \%, phần trăm; Sử dụng Kiểm định Chi-square; $p$, mức ý nghĩa thống kê; NA, Nonaplicable- Không áp dụng được.

\section{BÀN LUẬN}

Theo nghiên cứu của chúng tôi, nhóm tuổi từ 40 - 59 chiếm tỷ lệ cao nhất 45,3\%; nhóm tuổi > 60 chiếm 36,8\%; nhóm tuổi 20 - 39 chiếm tỷ lệ $16,4 \%$. Nhóm tuổi < 20 chiếm tỷ lệ thấp nhất 1,5\%. Người bệnh là nam chiếm $55,2 \%$ người bệnh nữ chiếm 44,8\%. Người bệnh có trình độ văn hóa dưới THPT chiếm tỷ lệ cao nhất $80,6 \%$ người bệnh có trình độ học nghề, trung cấp/cao đẳng chiếm 14,4\% người bệnh có trình độ đại học/sau đại học chiếm tỷ lệ thấp nhất $5 \%$.

Năng lực sức khỏe của đối tượng nghiên cứu là 15,2 $\pm 12,5$. Năng lực sức khỏe và chất lượng cuộc sống không có tương quan với nhau với $p>0,05$. Năng lực sức khỏe điện tử (eHL) của đối tượng nghiên cứu có giá trị trung bình là $24,6 \pm 7,5$. Năng lực sức khỏe của người bệnh và chất lượng cuộc sống của người bệnh có tương quan với nhau với $p<$ 0,001 . Năng lực chế độ ăn lành mạnh điện tử trung bình là $8,3 \pm 3,7$. Chất lượng cuộc sống của người bệnh suy thận mạn có mối tương quan với năng lực sức khỏe, dinh dưỡng, chế độ ăn lành mạnh, sức khỏe tâm thần, thực hành phòng dịch COVID-19. Theo đó, người bệnh có năng lực sức khỏe, dinh dưỡng, chế độ ăn lành mạnh, sức khỏe tâm thần và thực hành phòng dịch càng cao thì chất lượng cuộc sống càng cao.

Sức khỏe tâm thần có $91,5 \%$ người bệnh có điểm số GAD < 8; chỉ có 8,5\% người bệnh có điểm số $G A D>8$ là có rối loạn lo âu về bệnh tật và dịch bệnh COVID 19. Điểm trung bình chất lượng cuộc sống của nhóm người bệnh có điểm GAD < 8 lớn hơn so với điểm trung bình chất lượng cuộc sống của nhóm GAD $>8$ có ý nghĩa thống kê với $p<0,001$. Khi sử dụng bộ câu hỏi $\mathrm{PHQ}$ - 9 có $89,6 \%$ người bệnh suy thận mạn không có rối loạn trầm cảm, 10,4\% người bệnh suy thận mạn có rối loạn trầm cảm với thang điểm $\mathrm{PHQ}$ - 9 dưới $\geq 10$. Điểm trung bình chất lượng cuộc sống của người bệnh không có rối loạn trầm cảm là 54,2 cao hơn điểm trung bình chất lượng cuốc sống của người bệnh có rối loạn trầm cảm là 29,7 có ý nghĩa thống kê với $p<0,001$. Kết quả nghiên cứu của chúng tôi cho thấy rối loạn trầm cảm có ảnh hưởng tới chất lượng cuộc sống của người bệnh suy thận mạn.

Chất lượng cuộc sống là yếu tố tiên đoán cho sức khỏe của người bệnh suy thận mạn và là yếu tố quan trọng trong đánh giá chất lượng chăm sóc. 
Theo nghiên cứu của chúng tôi, đánh giá chất lượng cuộc sống của người bệnh suy thận mạn lọc máu chu kỳ sử dụng bộ câu hỏi SF 36 , kết quả cho thấy, điểm trung bình hoạt động thể chất là 42,4 $\pm 24,7$; Giới hạn vai trò do sức khỏe thể chất $56,3 \pm 48,9$; Giới hạn vai trò do vấn đề cảm xúc $80,3 \pm 37,9$; Năng lượng/mệt mỏi 49,6 \pm 9,3; Tình cảm tốt đẹp 53,5 $\pm 7,6$; Hoạt động xã hội 56,6 \pm 15,8; Đau 53,5 \pm 22,8; Sức khỏe tổng thể 39,6 \pm 19,3. Tổng điểm chất lượng cuộc sống của nhóm người bệnh nghiên cứu ở mức trung bình 50,2 \pm 15,0.

Các yếu tố liên quan đến sức khỏe tâm thần của người bệnh suy thận mạn: Về tuổi tỷ lệ trầm cảm và lo âu ở nhóm tuổi từ 40 - $\geq 60$ là cao nhất tuy nhiên sự khác biệt so với các nhóm tuổi khác không có ý nghĩa thống kê với p > 0,05; Địa vị xã hội: tỷ lệ trầm cảm ở nhóm người bệnh có địa vị xã hội thấp cao hơn so với tỷ lệ trầm cảm ở nhóm người bệnh có địa vị xã hội cao với $p<0,05$. Tỷ lệ lo âu ở nhóm người bệnh có địa vị xã hội cao tương đương với tỷ lệ lo âu ở nhóm người bệnh có địa vị xã hội thấp, với p > 0,05; Nghi nhiễm COVID - 19: Kết quả nghiên cứu của chúng tôi cho thấy tỷ lệ trầm cảm và lo âu của nhóm người bệnh có nghi ngờ nhiễm COVID - 19 là cao hơn so với nhóm người bệnh không có nghi nhiễm COVID - 19 có ý nghĩa thống kê với $p<0,05$; Nghề nghiệp: Kết quả nghiên cứu của chúng tôi cho thấy tỷ lệ người bệnh lo âu và trầm cảm ở các nhóm nghề nghiệp là tương đương nhau với $p$ $>0,05$. Điều này cho thấy nghề nghiệp không ảnh hưởng tới mức độ lo âu và trầm cảm của người bệnh suy thận mạn; Hoạt động thể lực so với trước dịch bệnh COVID-19: Theo nghiên cứu của chúng tôi nhóm người bệnh có mức hoạt động thể lực là chưa bao giờ, bỏ hoặc ít hơn và nhóm người bệnh có mức hoạt động thể lực không thay đổi hoặc nhiều hơn có mức độ lo âu trầm cảm tương đương nhau với $p>0,05$.
Điều này cho thấy mức độ hoạt động thể lực không ảnh hưởng tới mức độ lo âu và trầm cảm của người bệnh suy thận mạn; Thay đổi chế độ ăn so với trước dịch bệnh COVID-19: Kết quả nghiên cứu cho thấy mức độ lo âu và trầm cảm ở nhóm người bệnh có chế độ ăn kém lành mạnh hơn và nhóm người bệnh có chế độ ăn không thay đổi/ lành mạnh hơn là tương đương nhau với $p>0,05$. Điều này cho thấy chế độ ăn không ảnh hưởng tới mức độ lo âu và trầm cảm của người bệnh suy thận mạn.

\section{KÉT LUÂN}

Chất lượng cuộc sống của người bệnh suy thận mạn ở mức độ trung bình 50,2 \pm 15,0. Trong đó, giới hạn vai trò do vấn đề cảm xúc ở mức cao nhất $80,3 \pm 37,9$; sức khỏe tổng thể ở mức thấp nhất 39,6 \pm 19,3.

Chất lượng cuộc sống của người bệnh suy thận mạn có mối tương quan với năng lực sức khỏe, dinh dưỡng, chế độ ăn lành mạnh, sức khỏe tâm thần, thực hành phòng dịch COVID-19.

\section{TÀI LIẸU THAM KHẢO}

1. Nguyễn Thị Ngọc và cộng sự (2018). Chất lượng cuộc sống của bệnh nhân đang lọc máu định kỳ. Tạp chí Y Học TP. Hồ Chí Minh phụ bản 22(5) : 125 - 131.

2. Ngô Huy Hoàng Lê Thị Huyền (2016). Chất lượng cuộc sống của người bệnh suy thận mạn điều trị tại bệnh viện Hữu Nghị Việt Nam - Cu Ba Đồng Hới năm 2016. Khoa Học Điều Dưỡng 1(2) : 58 - 65.

3. Duong TV, Nguyen TTP, Pham KM, Nguyen KT, Giap MH, Tran TDX, et al. Validation of the Short-Form Health Literacy Questionnaire (HLS-SF12) and Its Determinants among People Living in Rural Areas in Vietnam. Int $J$ Environ Res Public Health 2019 16(18):3346.

4. Gallagher, T.H. (2020). Schleyer, A.M. 
"We Signed Up for this!" - Student and Trainee Responses to the Covid-19 Pandemic. N.Engl. J. Med. 2020.

5. Hays RD, Kallich J, Mapes D, et al. Kidney Disease Quality of Life Short Form (KDQOL$\mathrm{SF})$, Version 1.3: a manual for use and scoring. Santa Monica, CA: Rand. 1997;39.

6. Hoang C.Minh. Minh H.Nguyen, Binh N.Do, Cuong Q.Tran, Thao TP Nguyen et al (2020). People with Suspected COVID-19 Symptoms Were More Likely Depressed and Had Lower Health-Related Quality of Life: The Potential Benefit of Health Literacy https://www. mdpi.com/2077-0383/9/4/965/htm.

7. Jin W, Yu H. A study of the reliability and validity of SF-36 scale on evaluating health of population. Chin Health Resour. 2012;15:265267.

8. Hays RD, Morales LS. The RAND-36 measure of health-related quality of life. Annals of medicine. 2001;33(5):350-357.

9. Mackert, M. (2015). Introduction to a Colloquium: Challenges and Opportunities in Advancing Health Literacy Research. Health Commun. 30 : 1159-1160.

10. Norman CD, Skinner HA. eHEALS: The eHealth Literacy Scale. J Med Internet Res 2006 8(4):e27.

11. Nguyen HT, Do BN, Pham KM, Kim GB, Dam HTB, Nguyen TT, et al (2020). Fear of COVID-19 Scale-Associations of Its Scores with
Health Literacy and Health-Related Behaviors among Medical Students. Int J Environ Res Public Health 2020 17(11):4164.

12. Plummer, F.; Manea, L.; Trepel, D.; McMillan, D. (2016). Screening for anxiety disorders with the GAD-7 and GAD-2: a systematic review and diagnostic metaanalysis. Gen. Hosp. Psychiatry, 39 : 24-31.

13. Raynor, D.K. (2012). Health literacy. BMJ, 344, e2188.

14. RAND Medical Outcomes Study. 36Item Short Form Survey (SF-36) Scoring Instructions. https://www.rand.org/health care/ surveys tools/mos/36-item-short-form/scoring. html. Accessed March, 2021.

15. Sørensen, K et al (2012). Health literacy and public health: a systematic review and integration of definitions and models. BMC Public Health, 12, 80.

16. Vander Zee KI, Sanderman R, Heyink JW, de Haes $\mathrm{H}$. Psychometric qualities of the RAND 36-Item Health Survey 1.0: a multidimensional measure of general health status. International journal of behavioral medicine.1996;3(2):104-122.

17. Vivekanand Jha (2009). Current status of chronic kidney disease care in Southest Asia, Seminars in Nephrology, 29(5), 487-496.

18. Wang, C.; Horby, P.W.; Hayden, F.G.; Gao, G.F. (2020). A novel coronavirus outbreak of global health concern. Lancet, 395, 470-473. 


\section{Summary}

\section{QUALITY OF LIFE OF CHRONIC KIDNEY DISEASE PATIENTS UNDERGOING ROUTINE HEMODIALYSIS THERAPY AT THE AGRICULTURE GENERAL HOSPITAL DURING THE COVID-19 PANDEMIC AND ASSOCIATED FACTORS}

Objectives: This study investigates the quality of life (QoL) and associated factors in patients with chronic kidney disease (CKD) who require routine hemodialysis at the Agriculture General Hospital. Methods: This descriptive cross-sectional study was conducted on a convenient sample of 201 patients from February 2020 to October 2020. Results: The patients' QoL was at the average level (mean $=50.2, S D=15.0)$. The mean score for role limitations caused by emotional problems was found highest (mean=80.3, SD=37.9), while the figure for general health was the lowest (mean= 39.6, SD= 19.3). The QoL of CKD patients is associated with their health literacy, nutrition, healthy diets, mental health, and practice of COVID-19 prevention. Conclusion: The CKD patients' QoL was at the average level. There were associations of factors such as health literacy, nutrition, healthy diets, mental health, and practice of COVID-19 with the QoL of CKD patients.

Keywords: COVID-19 pandemic, patients with chronic kidney disease. 